\title{
Carcinomas escamosos com miíase, uma nova tendência?
}

\author{
Squamous cell carcinomas with myiasis, a new trend?
}

Felipe Tavares Rodrigues ${ }^{1}$, Marcos Roberto Pereira Cardozo ${ }^{1}$, Larissa Raquel Klemig e Silva ${ }^{1}$, Valéria Magalhães Aguiar², Claudia Soares Lessa²

\begin{abstract}
RESUMO
I mportância do problema: Este artigo se propõe a descrever dois casos de miíase em feridas neoplásicas de carcinomas escamosos, uma associação rara que vem se tornando comum. Comentários: Esta associação deve-se as altas prevalências de HPV, baixas condições socioeconômicas e de higiene, além do manejo inadequado de feridas e do descaso dos homens para com sua saúde, os principais afetados quando o assunto é câncer orofaríngeo e de pênis.
\end{abstract}

Palavras-chave: Medicina Tropical. Oncologia. Mí́ase.

\begin{abstract}
Relevance: This article intends to describe two cases of myiasis on squamous cells neoplasic wounds, a rare association that are becoming more easily seen nowadays. Comments: This association due to high HPV serum prevalences, low social and hygiene conditions, in addition to the precarious wounds care and men's health seek relapse, the mainly affected when the issue is oropharynx and penis cancers.
\end{abstract}

Key-words: Tropical Medicine. Medical Oncology. Myiasis.

\section{INTRODUÇÃO}

Míase é a infestação de tecidos de mamíferos por larvas de moscas. Na América, a maioria dos casos se deve a espécie Cochliomyia hominivorax (Coquerel, 1858) que se alimenta exclusivamente de tecidos vivos, outro agente comum é a Dermatobia hominis (Wiedemann, 1819), conhecida popularmente como berne, causando a miíase furuncular ${ }^{1}$.
Carcinomas malignos podem crescer rapidamente e provocar a perda da aderência intercelular epitelial formando as chamadas feridas neoplásicas, estas podem ocorrer em até $10 \%$ dos casos, na maioria em neoplasias de mama².

O Instituto Nacional do Câncer (INCA) registrou 14.700 novos casos de câncer de orofaringe no Brasil em 2018 sendo destes 11.200 do sexo masculino. Já de câncer de pênis estima-se que represente $2 \%$ de todos os casos de câncer
1. Escola de Medicina e Cirurgia do Rio de Janeiro, Universidade Federal do Estado do Rio de Janeiro UNIRIO

2. Departamento de Microbiologia e Parasitologia, Universidade Federal do Estado do Rio de Janeiro UNIRIO 
em homens no país, principalmente na região norte e nordeste ${ }^{3}$.

A pele humana é conhecida por eliminar metabólitos no ar, quando lesionada como por exemplo, pelo crescimento de um melanoma ou de outras neoplasias pode alterar esses metabólitos e atrair fêmeas de dípteros para deposição de seus ovos. A associação entre feridas neoplásicas e miíases é pouco descrita na literatura, sendo principalmente relatados os casos de tumores dermatológicos, tal associação pode causar inúmeras complicações como infecções graves e hemorragias se tornando uma emergência médica ${ }^{4,5,6}$. Em contrapartida, muitos países do mundo já se utilizam a terapia com larvas de moscas necrobiontófagas como as de Lucilia serricata, como terapia biológica para a cicatrização e até controle de microorganismos em diversos tipos de feridas ${ }^{7}$, esta terapia poderia ser utilizada até em alguns tumores dermatológicos in situ. Este relato de caso descreve dois carcinomas escamosos com patogênese relacionada à infecção pelo HPV com a subsequente infestação por miíase em feridas neoplásicas.

\section{RELATO DE CASO}

\section{Caso um}

Um homem de 42 anos de idade, com uma carga tabágica de 30 maços-ano e alcoolismo, foi admitido no Hospital Federal do Andaraí, no ano de 2015, Rio de Janeiro, com um câncer orofaríngeo estágio III, já com invasão de cadeias linfonodais cervicais e sinais de obstrução tumoral de vias aéreas, sendo preciso realizar entubação endotraqueal e colocação de sonda nasogástrica para alimentação, pois o paciente estava com caquexia e saturação de $\mathrm{O}_{2}$ a $90 \%$. Três dias após a colocação de ventilação mecânica, múltiplas úlceras purulentas com 15 larvas de Cochliomyia hominivorax (Coquerel) surgiram no paciente. (Figura 1). O tratamento com ivermectina oral,além de piperacilina e tazobactam venoso para o combate da infecção secundária e o adequado tratamento quimioterápico paliativo a base de cisplatina foram administrados ao paciente após sua estabilização.

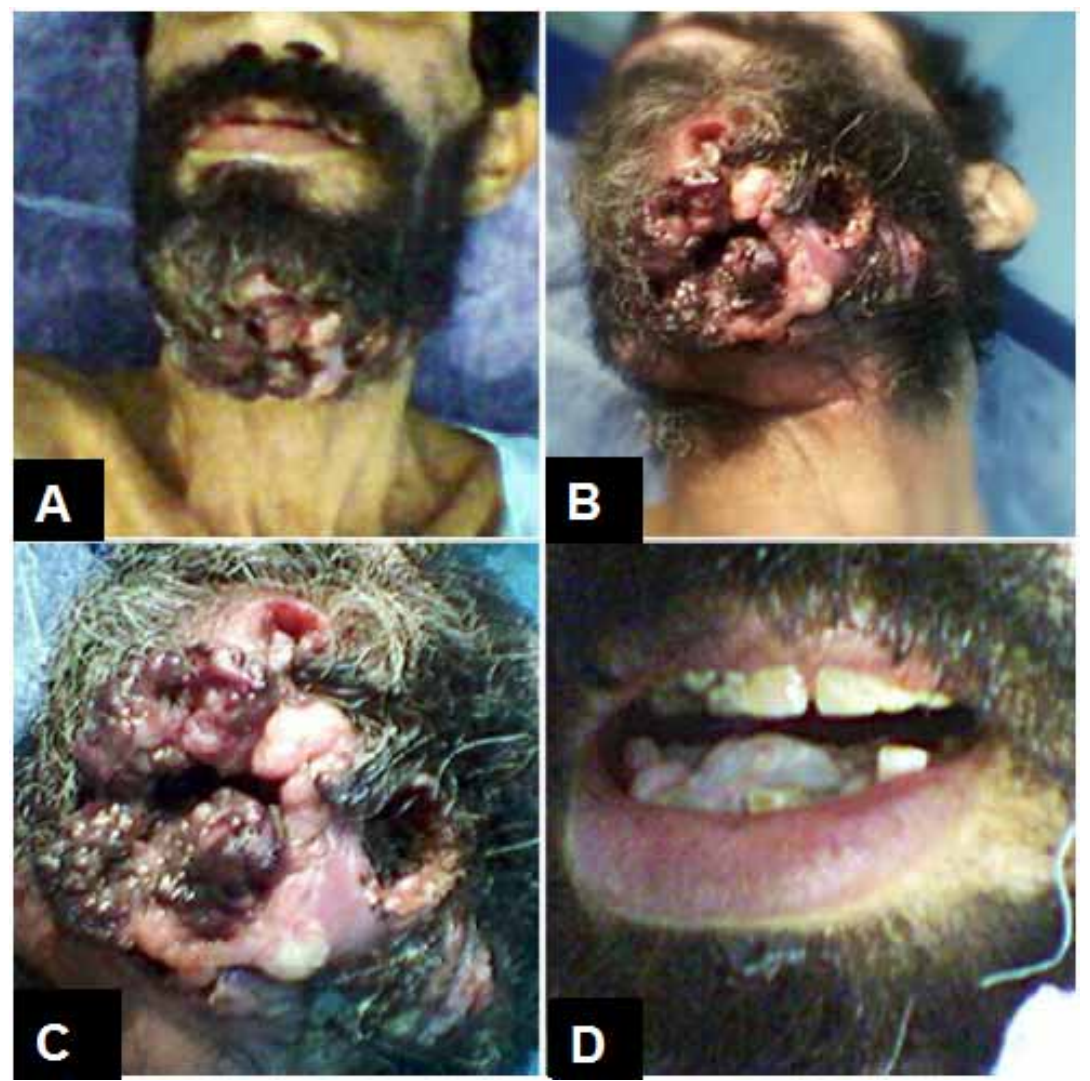

Figura 1: A, B, C, D - Diferentes perspectivas de um paciente com carcinoma orofaríngeo com multiplas ulcerações, massas exofíticas, perolas córneas e exudato purulento com larvas de míase. 


\section{Caso dois}

Paciente de 55 anos de idade, com histórico de carcinoma escamoso peniano, não cooperativo ao exame, com grau moderado de déficit cognitivo, diabetes melitus e precárias condições de higiene na admissão, foi internado com intensa dor no pênis. Ao exame pudemos perceber intensa hidrocele, adenopatia inguinal de origem infecciosa e retirar 27 larvas de Cochliomyia hominivorax. (Figura 2). Foi recomendado o trata- mento com ivermectina oral, além de tratamento antimicrobiano a base de ciprofloxacino oral, e debridamento cirúrgico da lesão através de uma penectomia total com uretrostomia perineal e futuras sessões de quimioterapia neoadjuvante a base de bleomicina.

Todos os pacientes descritos tiveram a soro positividade para IgG HPV confirmada. Larvas e moscas foram retiradas e levadas para classificação através de chaves taxonômicas em laboratório $^{8,9}$. (Figura 3).

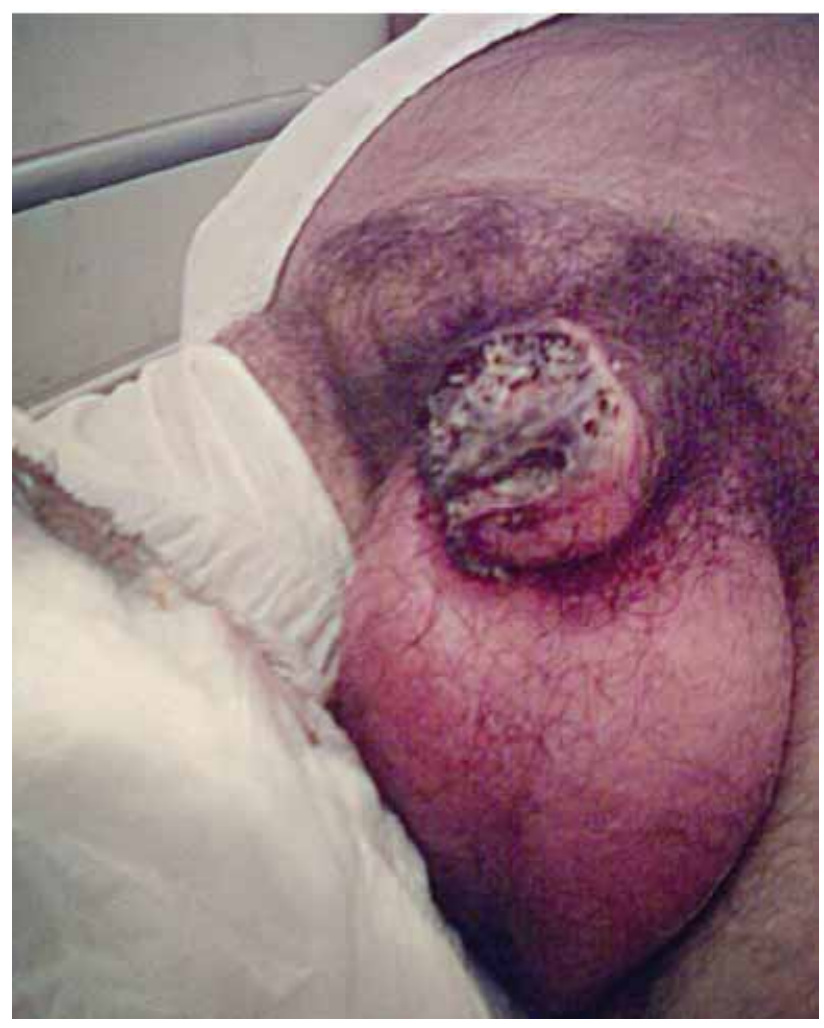

Figura 2: Paciente com carcinoma escamoso peniano, intensa hidrocele e destruição da região da glande por larvas de miíase.

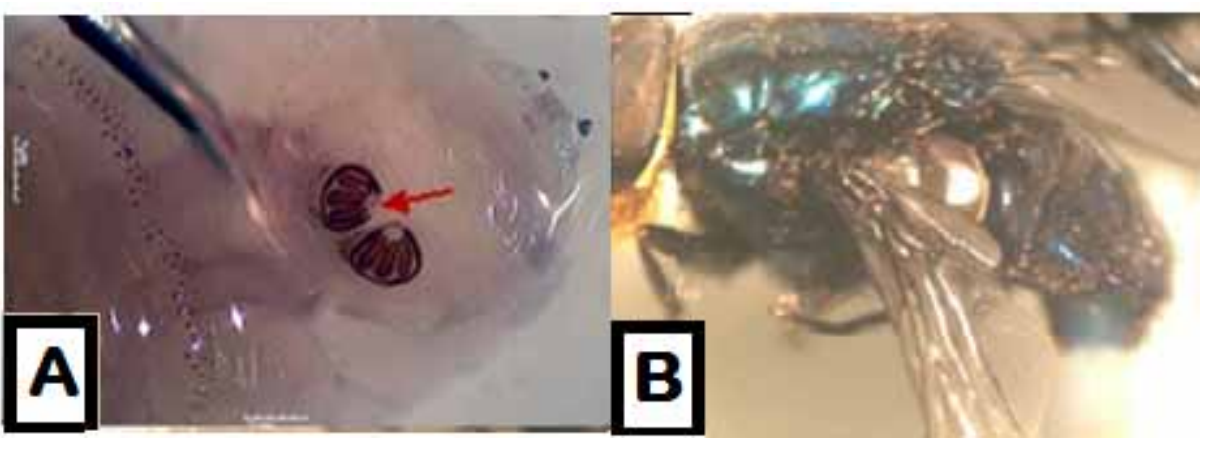

Figura 3: A- Larva de C. hominivorax com seus típicos ductos traqueais dorsais. B- Adulto com a cor verde metalizada e suas listras negras no dorso. 


\section{DISCUSSÃO}

Carcinomas de células escamosas estão tipicamente relacionados à perda da integridade tecidual devido ao crescimento tumoral e a formação de feridas neoplásicas. Assim como descrito por nosso grupo de pesquisa em outro artigo sobre um carcinoma ductal de mama infestado por miíase ${ }^{10}$. Questões socioeconômicas e de higiene estão implicadas tanto na infecção por mí́ase quanto na infecção pelo HPV e o desenvolvimento de certos tipos de câncer como o de orofaringe e de pênis ${ }^{11}$. $O$ homem como provedor do sustento de muitas famílias relega muitas das vezes a própria saúde, procurando assistência médica na maioria dos casos em estágios muito avançados da doença, assim como descrito nos casos acima.

Existe uma correlação importante entre a carcinogênese e os grupos 16 e 18 do Papilomavirus Humano (HPV). Sendo importante fator de risco para o câncer orofaríngeo, de colo de útero, de pênis, de ânus e de vulva ${ }^{12}$. Um estudo realizado por Koifman e colaboradoradores em 201713, já tinha sinalizado para a associação entre casos de câncer de pênis e miíase, contudo, a partir de nossos casos previamente publicados, podemos suscitar a hipótese de uma tendência de todos os carcinomas escamosos não somente penianos à infestação com larvas de dípteros, pois formam feridas neoplásicas.

\section{CONCLUSÃO}

É imprescindível para o combate das situações descritas neste relato de caso, a promoção de políticas para a saúde masculina, a vacinação em massa da população contra o HPV, o incentivo para o rastreio precoce de neoplasias além de medidas de educação sanitária, saneamento básico e cuidados básicos com feridas.

\section{REFERENCES}

1. Linhares AX. Miíases. In: Neves DP, Mello A, Genaro $\mathrm{O}$, Linardi PM, editores. Parasitologia humana. 10 ed. São Paulo: Atheneu; 2000.

2. Meaume S, Fromantin L, Teot L. Neoplastic wounds and degenerescence. J Tissue Viability. 2013;22:122-30. doi: 10.1016/j.jtv.2013.07.001.

3. INCA [homepage na Internet]. Rio de Janeiro: Instituto Nacional do Câncer, Inc.; [consultado 2018 Fev 6].Disponível em: http://www. http:// www2.inca.gov.br.

4. Abaffy $T$, Duncan R, Riemer DD, Tietje O, Elgart G, Milikowski C, DeFazio RA. Differential volatile signatures from skin, naevi and melanoma: a novel approach to detect a pathological process. PLoS One 2010;5:e13813. doi: 10.1371/ journal. pone.0013813.

5. Villwock JA, Harris TM. Head and neck myiasis, cutaneous malignancy, and infection: a case series and review of the literature. J Emerg Med. 2014; 47: e37-41

6. Srivastava R, Devi P, Thimmarasa VB, Jayadev S. Flies blown disease - oral myiasis. Indian J Dent Res. 2011;22:615.

7. Nasoori A, Hoomand R. Maggot debridement therapy for an electrical burn injury with instructions for the use of Lucilia sericata larvae. J Wound Care. 2017; 26: 734-41.

8. Serra-Freire NM, Mello RP. Entomologia e acarologia na medicina veterinária. Rio de Janeiro: L.F. Livros de Veterinária; 2006. 200p.

9. Mello RP. Chave para a identificação das formas adultas das espécies da família Calliphoridae (Diptera, Brachycera, Cyclorrhapha) encontradas no Brasil. Entomol Vectores. 2003; 10:255-68.

10. Rodrigues FT, Klemig LR, Cardozo MRP, Alves PC, Aguiar VM, Lessa CS. Myiasis associated with an invasive ductal carcinoma of the left breast: case study. Rev Inst Med Trop São Paulo. 2017; 59:1-6.

11. Parkin DM, Bray F. HPV Vaccines and Screening in the Prevention of Cervical Cancer. Vaccine. 2006; 24: S11-S25.

12. Chernock RD, Wang X, Gao G, Lewis JS, Zhang Q, Thorstad WL. Detection and significance of human papillomavirus, CDKN2A(p16) and $\operatorname{CDKN1A}(\mathrm{p} 21)$ expression in squamous cell carcinoma of the larynx. Mod Pathol. 2013;26:223-31.

13. Koifman L, Barros R, Schulze L, Ornellas AA, Favorito LA. Myiasis associated with penile carcinoma: a new trend in developing countries? Int Braz J Urol. 2017; 43: 73-9. 